\title{
Caracterização fisiográfica e avaliação do uso e ocupação das APP da microbacia do ribeirão das Antas
}

\author{
Alan Ferreira Batista ${ }^{1}$ \\ Getulio Teixeira Batista ${ }^{2}$
}

\author{
${ }^{1}$ USP-ESALQ, Universidade de São Paulo - Escola Superior de Agricultura "Luiz de \\ Queiroz”, Departamento de Ciências Florestais, Av. Pádua Dias, 11, 13418-900 - Piracicaba, \\ SP, Brasil \\ alan.batista@usp.br
}

${ }^{2}$ UNITAU, Programa de Pós-Graduação em Ciências Ambientais

Estrada Mun. Dr. José Luiz Cembranelli, 5.000, 12080-010 - Taubaté, SP, Brasil

getulio@agro.unitau.br

\begin{abstract}
The objective of this article is to describe some physical properties of the Antas stream watershed and evaluate the occurrence and land use of its Permanent Preservation Areas (PPA) using geotechnologies. Methods included the application of the SPRING software package to produce maps of land use and land cover based on Project Una data basis and pertinent legislation. The morphometric properties of the drainage basin included the estimation of area, perimeter, largest length, circularity index, maximum elevation range, relief ratio, sinuosity index, and drainage density based on metric operations, measures of classes and crossed tabulation using several SPRING functions. Results indicate that hill top and stream margins are the dominant PPA categories while pasture is dominant inclusive in PPA in this watershed. More than 64\% of watershed area is PPA, therefore, agriculture and livestock exploration is very restricted by legislation. About $68 \%$ of PPA is covered by pasture instead of forest and $84 \%$ of roads are within a $100 \mathrm{~m}$ buffer from water bodies.
\end{abstract}

Palavras-chave: SIG, manejo de bacias, APP, SPRING, uso da terra.

\section{Introdução}

A exploração inapropriada dos ecossistemas resulta na degradação dos recursos naturais, principalmente do solo e dos recursos hídricos, diminuindo a qualidade de vida da população, causando impactos sociais principalmente naqueles que dependem da terra para sobreviver. Para o planejamento eficiente do uso e ocupação do solo, faz-se necessário o uso de informações integradas em escala detalhada. Nesse contexto, insere-se a possibilidade de utilizar as microbacias hidrográficas como unidade de planejamento para o manejo racional dos recursos naturais. No planejamento de uma microbacia são indispensáveis as caracterizações fisiográfica e sócio-econômica, além da identificação das práticas do uso atual, especialmente das áreas de preservação permanente (APP) que, por amparo legal, devem ser preservadas.

Segundo Meneses, no prefácio de Assad e Sano (1993), para acompanhar a dinâmica da ocupação e utilização do solo é preciso dispor de técnicas que facilitem a ordenação dessa ocupação e que sejam passíveis de tratamentos automatizados. Sheng et al. (1997) propõem o uso de SIGs para classificação e avaliação de bacias hidrográficas destacando a importância de ferramentas como o Modelo Digital do Terreno (MDT) na obtenção de parâmetros como limite da bacia, elevações e características das encostas que podem ser combinadas com outras informações, como mapa geológico e de solos, para derivar mapas temáticos úteis no planejamento do manejo adequada das microbacias.

A principal fonte de dados que subsidiou este artigo, foi um trabalho desenvolvido no Departamento de Ciências Agrárias da UNITAU conhecido como "Projeto Una" (Batista et al., 2002). Este projeto contém um banco de dados ambientais com informações 
georreferenciadas sobre o meio físico, uso da terra e dos recursos hídricos na bacia hidrográfica do rio Una que é formada por sete contribuintes, sendo o Antas um deles.

O presente trabalho teve como objetivo a caracterização fisiográfica, a quantificação das APPs e a avaliação do uso e ocupação solo da microbacia hidrográfica do ribeirão das Antas por meio da utilização de geotecnologias.

\section{Metodologia}

O trabalho foi desenvolvido no Instituto de Pesquisas Ambientais em Bacias Hidrográficas (IPABHi) e no Laboratório de Geoprocessamento da UNITAU (LAGEO), com base em ferramentas do aplicativo SPRING (CÂMARA et al., 1996), com o objetivo de realizar a caracterização fisiográfica da microbacia hidrográfica do ribeirão das Antas que possui área total de 2936 ha (Figura 1).

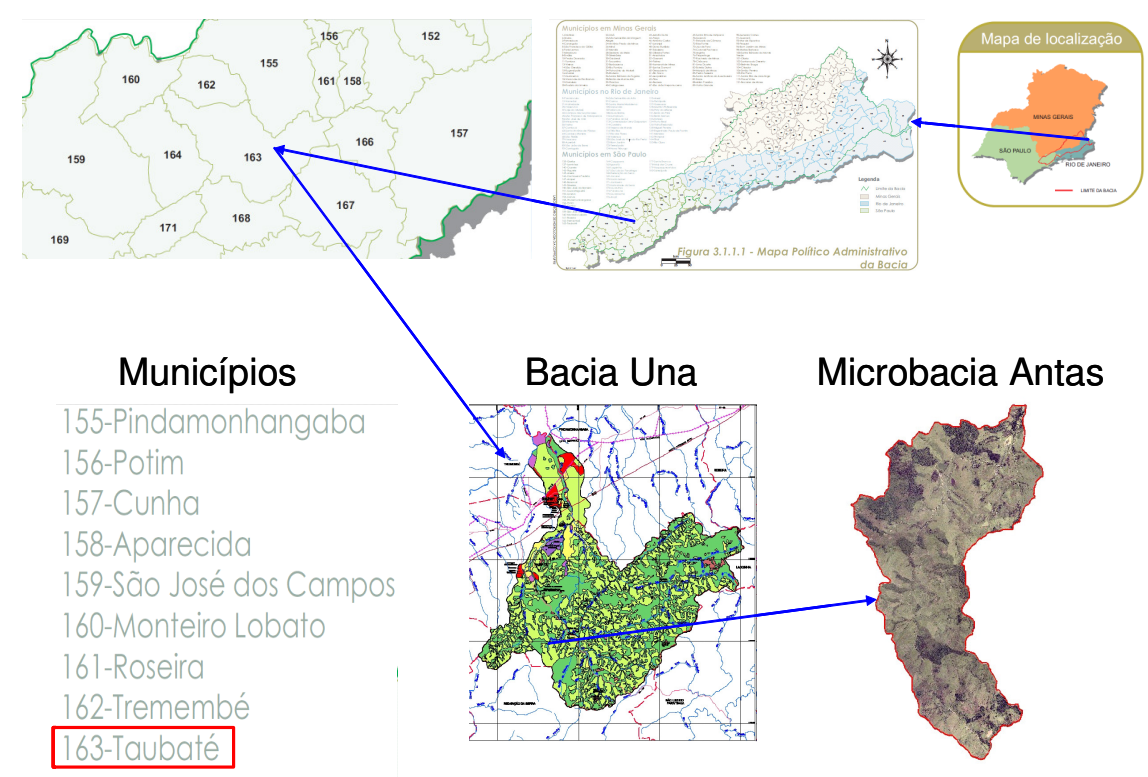

Figura 1. Localização da microbacia do ribeirão das Antas, imagem sintética, mosaico elaborado no aplicativo SPRING a partir de ortofotos digitais (resolução espacial de 0,60 metros, obtida em 2003 - Projeto Una).

As caracterizações físicas e morfométricas da microbacia foram determinadas por meio de geoprocessamento da base de dados do "Projeto Una" (BATISTA et al., 2002).

Foram usadas diversas ferramentas do aplicativo SPRING para a elaboração do mapa de uso e ocupação do solo a partir da base de dados do "Projeto Una". Para o tratamento e análise de dados utilizaram-se ferramentas temáticas, como edição vetorial e matricial para a delimitação de objetos incluindo linhas e polígonos para identificar as áreas de uso e cobertura da microbacia. No Projeto Una, o mapa de declividade foi baseado na informação plano-altimétrica das cartas do IGC, com curvas de nível a cada $5 \mathrm{~m}$. As APPs de topo de morro foram cartografadas a partir da identificação das linhas de cumeadas e identificação dos morros com base no Modelo de Elevação do Terreno. Para as caracterizações físicas e morfométricas da microbacia, foram utilizadas diversas ferramentas do SPRING como operações métricas, medidas de classes, tabulação cruzada e extração de topos. $\mathrm{O}$ mapeamento das Áreas de Preservação Permanente (APPs) foram delimitadas a partir dos dados digitalizados da base cartográfica em escala 1:10.000 e foi baseada na Lei Federal $n^{\circ}$. 
4.771, de 1965 e na Resolução CONAMA no 303, de 2002 e seguiu a metodologia descrita por Catelani e Batista (2007) e Oliveira et al. (2006). As variáveis analisadas para a caracterização física da microbacia foram:

a) Área (A) e perímetro (P)

São parâmetros fundamentais utilizados para o cálculo de outras variáveis morfométricas e são definidos com base na linha de cumeada que delimita o divisor de águas da microbacia.

b) Maior comprimento (L) e largura média (Dm)

Estas duas variáveis, expressas em $\mathrm{km}$, foram determinadas seguindo os critérios adotados por Fontes (1997), sendo o maior comprimento representado pelo comprimento do maior eixo longitudinal da bacia e a largura média resultante da divisão da área pelo maior comprimento.

c) Índice de circularidade (Ic)

Este índice foi inicialmente proposto por Miller (1953 apud Christofoletti, 1974) e é definido como a razão entre a área da bacia e a área do círculo de igual perímetro (Ac). Este índice tem significado semelhante ao índice de forma (CHRISTOFOLETTI, 1969 e TAVARES e QUEIROZ, 1981) e ao coeficiente de compacidade (VILLELA e MATTOS, 1980) que correlacionam o perímetro da bacia com a sua área. O índice de circularidade (Equação 1) indica que à medida que o valor se aproxima de 1, a bacia tende à forma circular e, portanto, é mais sujeita à inundação.

$$
\mathrm{Ic}=\mathrm{A} / \mathrm{Ac}
$$

\section{d) Amplitude altimétrica máxima $(\mathrm{Hm})$ e relação de relevo $(\mathrm{Rr})$}

Estas duas variáveis estão relacionadas com as variações topográficas da bacia e foram apresentadas inicialmente por Schumm (1956). A amplitude altimétrica máxima corresponde à diferença, em metros, entre a altitude do exultório e o ponto mais alto no divisor de águas. A relação de relevo relaciona a amplitude altimétrica com o maior comprimento (L), indicando que quanto mais elevado o seu valor, maior o desnível entre a cabeceira e a foz. Os estudos efetuados por Patton \& Baker (1976) em bacias com altos e baixos potenciais às inundações indicaram a relação de relevo (Equação 2), densidade de drenagem e ordem dos canais como as três variáveis morfométricas mais influentes na indicação de bacias com alto potencial à inundação.

$$
\mathrm{Rr}=\mathrm{Hm} / \mathrm{L}
$$

\section{e) Índice de sinuosidade (Si)}

Segundo Villela e Mattos (1975) este índice, que descreve o grau de sinuosidade ou divagação dos cursos d'água, constitui um fator controlador da velocidade de escoamento das águas. Corresponde à razão entre o comprimento do rio principal da bacia $\left(\mathrm{L}_{\text {rio }}\right)$ e o seu comprimento vetorial $\left(\mathrm{L}_{\mathrm{vet}}\right)$ e pode ser calculado pela seguinte expressão (Equação 3):

$$
\mathrm{Si}=\mathrm{L}_{\text {rio }} / \mathrm{L}_{\mathrm{vet}}
$$

\section{f) Densidade de drenagem (Dd)}

Foi descrita por Horton (1945) como sendo a relação entre o comprimento total dos canais $(\mathrm{Lt})$ pela área da bacia hidrográfica $(\mathrm{A})$. A variável retrata a disponibilidade de canais para o escoamento linear das águas e o grau de dissecação do relevo resultante da atuação da rede de drenagem. A Equação 4 para o cálculo da densidade de drenagem é:

$$
\mathrm{Dd}=\mathrm{Lt} / \mathrm{A}
$$




\section{Resultados e Discussão}

Uma vez que os mapas das APP's (Figura 2), da cobertura vegetal e uso do solo (Figura 3) e de declividade (Figura 4) da microbacia do ribeirão das Antas estejam disponíveis, é possível usando ferramentas do SPRING como "medidas de classes" se obter uma síntese dos dados de APP (Tabela 1), assim como de uso e cobertura do solo (Tabela 2) e com a função "Tabulação cruzada", se sobrepor esses mapas georreferenciados da bacia para se fazer o cruzamento desses dois dados e se obter uma síntese do uso e cobertura do solo nas APPs (Tabela 3).

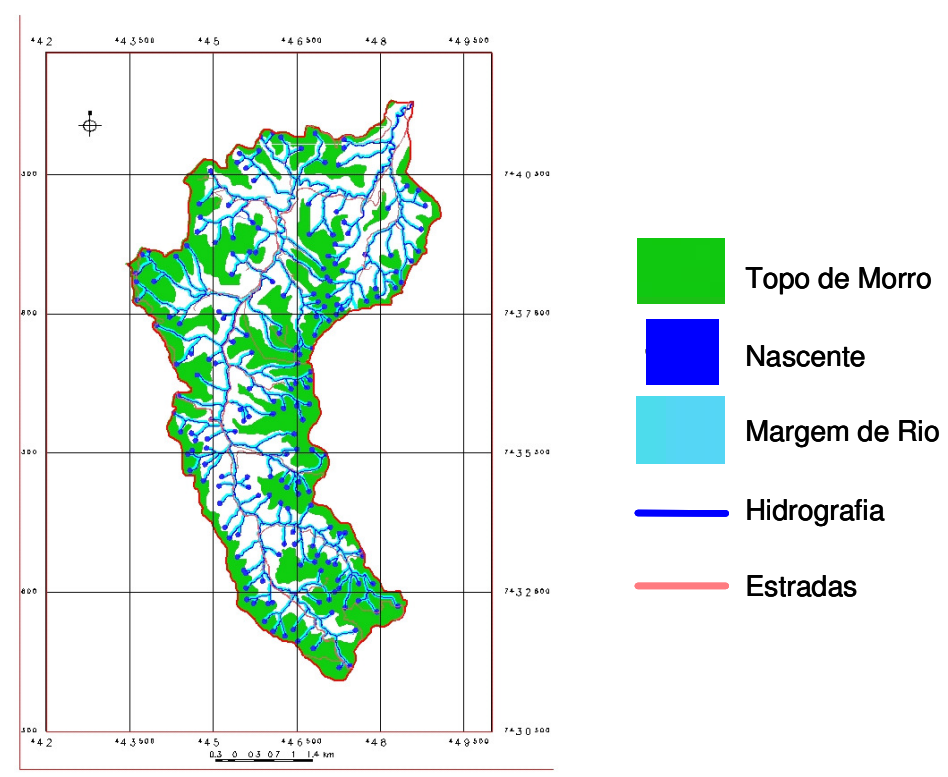

Figura 2. Mapa das Áreas de Preservação Permanente da Microbacia do ribeirão das Antas.
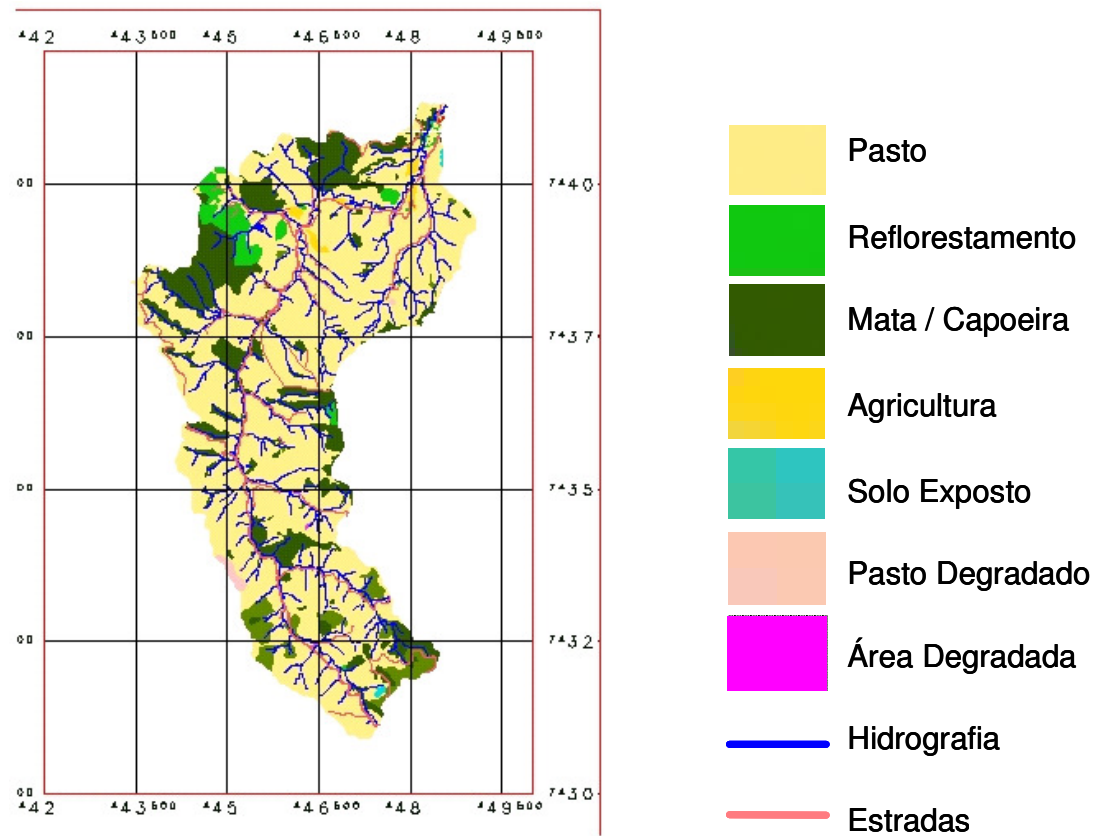

Figura 3. Mapa da cobertura do solo obtido pela classificação da microbacia do ribeirão das Antas. 


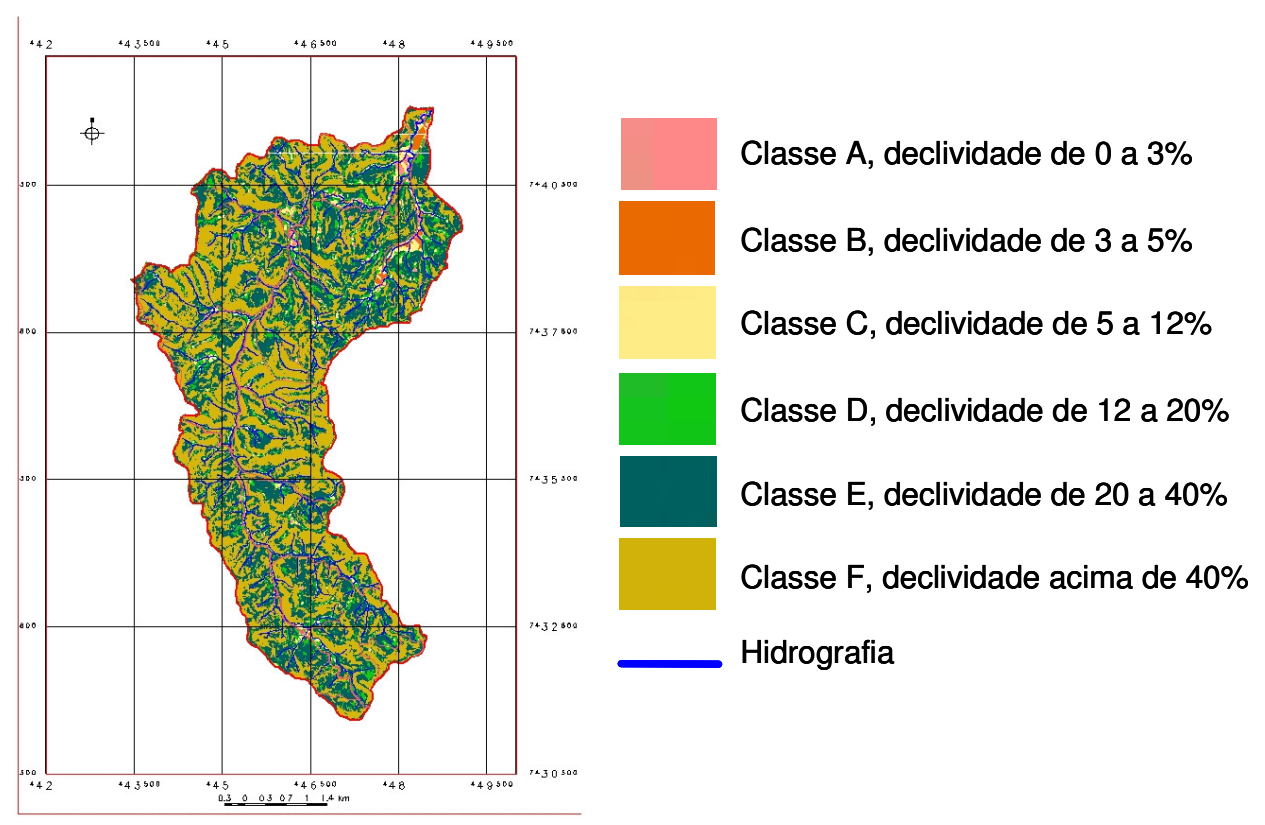

Figura 4. Mapa de declividade da microbacia obtido pelo tratamento do MDT obtido a partir de cartas do IGC, 1:10.000.

Tabela 1. Estimativa das ocorrências das diferentes classes de APP na microbacia do ribeirão das Antas.

\begin{tabular}{l|c|c}
\hline \multicolumn{1}{c|}{ APP } & Área em ha & \% de APP \\
\hline Nascente & 148 & 7,85 \\
Margens & 548 & 29,0 \\
Topo de morro & 1185 & 62,6 \\
Declividade & 8 & 0,43 \\
Lago/Lagoas & 2 & 0,12 \\
\hline Total & $\mathbf{1 8 9 1}$ & $\mathbf{1 0 0}$ \\
\hline
\end{tabular}

Número de nascentes $=95$.

Área total de APP em relação à área total da Bacia $=64,5 \%$.

Tabela 2. Estimativa das áreas de ocorrência das diferentes classes de uso e cobertura do solo na microbacia do ribeirão das Antas.

\begin{tabular}{l|c|c}
\hline \multicolumn{1}{c|}{ Tipo de Uso } & Área em ha & \% da Classe de Uso \\
\hline Mata Capoeira & 531,1 & 18,1 \\
Agricultura & 19,7 & 0,7 \\
Corpos d'água & 2,3 & 0,1 \\
Reflorestamento & 87,6 & 3,0 \\
Solo Exposto & 3,5 & 0,1 \\
Área Degradada & 1,9 & 0,1 \\
Área Urbanizada & 0,5 & 0,0 \\
Pasto Sujo & 111,3 & 3,8 \\
Pasto Degradado & 11,4 & 0,4 \\
Pasto & 2166,7 & $\mathbf{7 3 , 8}$ \\
\hline Total & $\mathbf{2 9 3 5 , 8}$ & $\mathbf{1 0 0 , 0}$ \\
\hline
\end{tabular}


Tabela 3. Cruzamento entre os planos de informação de área de uso e ocupação do solo e área de APP em ha.

\begin{tabular}{l|r|c|c|c|c|c|c|c|c|c|c}
\hline APP USO & $\begin{array}{c}\text { Mata } \\
\text { Cap. }\end{array}$ & Agric. & Pasto & Reflor. & $\begin{array}{l}\text { Solo } \\
\text { Exp. }\end{array}$ & $\begin{array}{l}\text { Área } \\
\text { Degr. }\end{array}$ & $\begin{array}{l}\text { Área } \\
\text { Urban. }\end{array}$ & $\begin{array}{l}\text { Pasto } \\
\text { Sujo }\end{array}$ & $\begin{array}{l}\text { Pasto } \\
\text { Degr. }\end{array}$ & $\begin{array}{l}\text { Corpo } \\
\text { d'água }\end{array}$ & Total \\
\hline$>$ 45 graus & 7 & 0 & 1 & 0 & 0 & 0 & 0 & 0 & 0 & 0 & $\mathbf{8}$ \\
Lagoa & 0 & 0 & 2 & 0 & 0 & 0 & 0 & 0 & 0 & 0 & $\mathbf{2}$ \\
Nascente & 24 & 0 & 110 & 4 & 0 & 1 & 0 & 10 & 1 & 0 & $\mathbf{1 5 0}$ \\
Rio margem & 123 & 1 & 397 & 8 & 0 & 1 & 0 & 18 & 0 & 0 & $\mathbf{5 4 8}$ \\
Topo Morro & 261 & 3 & 790 & 49 & 2 & 0 & 0 & 67 & 9 & 0 & $\mathbf{1 1 8 1}$ \\
\hline \multicolumn{1}{c}{ Total } & $\mathbf{4 1 5}$ & $\mathbf{4}$ & $\mathbf{1 3 0 0}$ & $\mathbf{6 1}$ & $\mathbf{2}$ & $\mathbf{2}$ & $\mathbf{0}$ & $\mathbf{9 5}$ & $\mathbf{1 0}$ & $\mathbf{1}$ & $\mathbf{1 8 8 9}$ \\
\hline
\end{tabular}

As principais atividades econômicas na microbacia são: pecuária (Figura 5) e reflorestamento (Figura 6). Sobrepondo os dados dessas atividades com as áreas de APP's, observa-se que a maior parte da bacia não está em conformidade com o código florestal (Tabela 3).

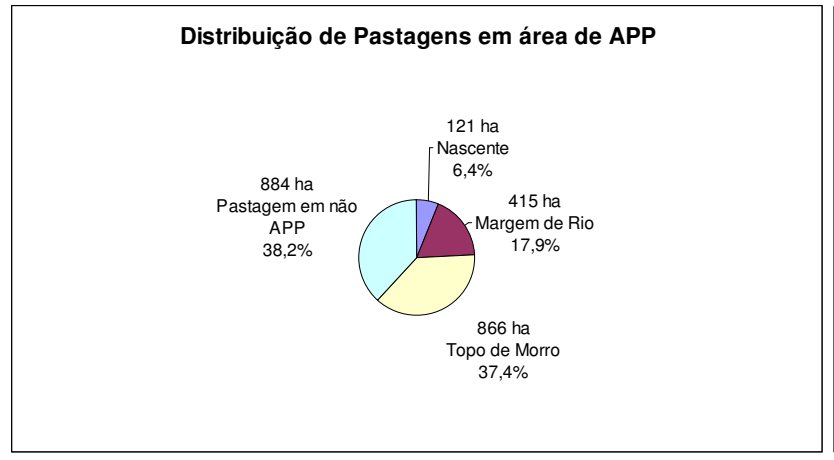

Figura 5. Distribuição de pastagem em área de APP.

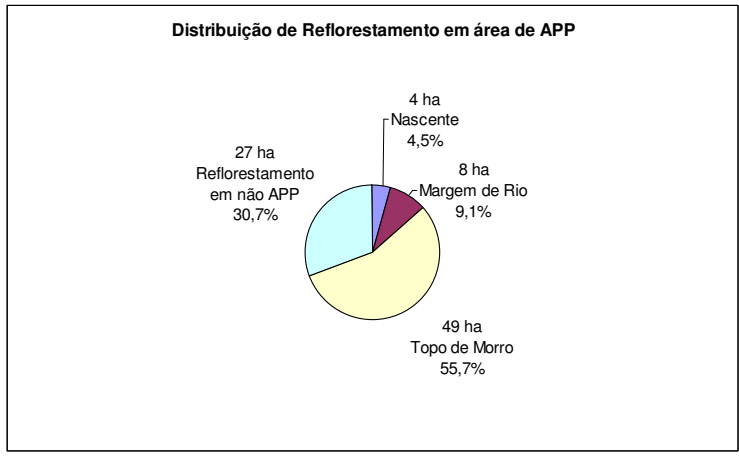

Figura 6. Distribuição de Reflorestamento em área de APP.

Estradas em áreas de APP e sem proteções de talude são muito suscetíveis à erosão e podem causar poluição lançando consideráveis cargas de sedimentos nos cursos d'água. Foi verificada a ocorrência de estradas em áreas de APP, assim como, verificadas as diferentes classes de estradas que se localizavam distantes até 100 metros dos cursos d'águas (Tabela 4). 
Tabela 4. Estimativa das áreas de ocorrência de estradas na microbacia do ribeirão das Antas, em relação à APP e a uma distância de até $100 \mathrm{~m}$ de riachos.

\begin{tabular}{l|c|c|c|c|c}
\hline Estrada (ha) & Total & Em APP & \% em APP & Em 100 m & \% em 100 m \\
\hline Caminho/Trilha & 16,0 & 9,4 & 58,9 & 12,0 & 75,1 \\
Estrada Não Pav. & 16,7 & 9,4 & 60,5 & 15,5 & 92,8 \\
Estrada Pav. & 0,4 & 0,1 & 28,9 & 0,3 & 89,5 \\
Auto Estrada (Rod.) & 0,1 & 0,0 & 0,0 & 0,1 & 100,0 \\
\hline Total de estradas & $\mathbf{3 3 , 2}$ & $\mathbf{1 8 , 9}$ & $\mathbf{5 7 , 0}$ & $\mathbf{2 7 , 9}$ & $\mathbf{8 4 , 3}$ \\
\hline
\end{tabular}

O perfil altimétrico (Figura 7) é uma importante variável na questão do manejo de erosão, drenagem e conservação do solo na bacia.

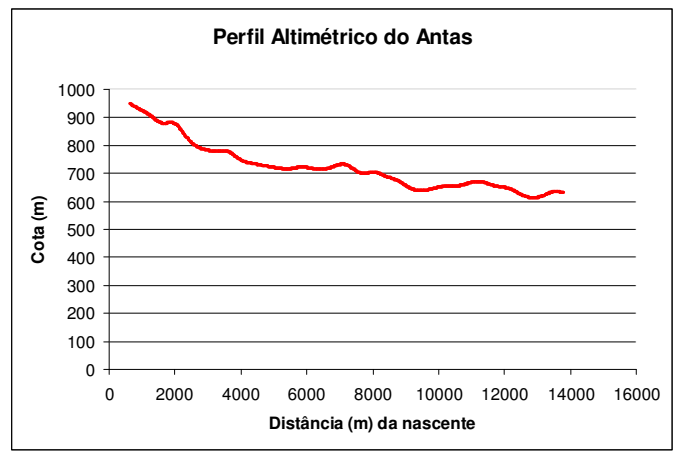

Figura 7. Perfil altimétrico do ribeirão das Antas, elaborado a partir do MDT obtido da carta do IGC 1:10.000.

A Tabela 5 apresenta as variáveis morfométricas estimadas para a caracterização física da microbacia do ribeirão das Antas.

Tabela 5. Cálculo das variáveis morfométricas da microbacia do ribeirão das Antas.

\begin{tabular}{l|c|c}
\hline Parâmetro & Valor do Índice & Unidade \\
\hline A (Área) & 2936 & $\mathrm{ha}$ \\
P (Perímetro) & 32,5 & $\mathrm{~km}$ \\
L (Maior Comprimento) & 18,7 & $\mathrm{~km}$ \\
Dm (Largura Média) & 1,6 & $\mathrm{~km}$ \\
Hm (Amplitude Alt. Máx.) & 400 & $\mathrm{~m}$ \\
Rr (Relação de Relevo) & 0,02 & $\mathrm{~m} / \mathrm{km}$ \\
Ic (Índice de Circularidade) & 0.4 & \\
Si (Índice de Sinuosidade) & 1,8 & $\mathrm{~km} / \mathrm{km}^{2}$ \\
Dd (Densidade de Drenagem) & 3,7 & \\
\hline
\end{tabular}

Pode-se inferir com base nos dados da Tabela 5 que a bacia não é sujeita à inundação (Ic $=0,4)$; possui alta sinuosidade $(\mathrm{Si}=1,8)$ em função da microbacia estar inserida sobre o escudo cristalino em uma região de mares de morros, o que condiciona relevos movimentados, com elevada amplitude altimétrica $(\mathrm{Hm}=400 \mathrm{~m})$ e densidade de drenagem $(\mathrm{Dd}=3,7)$ que indica que essa bacia é muito bem drenada, apesar da relação de relevo considerada baixa $(\mathrm{Rr}=0,02 \mathrm{~m} / \mathrm{km})$. 


\section{Conclusões}

O tratamento dos dados espaciais por meio de ferramentas do aplicativo SPRING se mostrou eficiente para a caracterização fisiográfica da bacia estudada, o que pode contribuir para a elaboração de um plano de manejo para o uso racional do solo visando à adequação da bacia ao Código Florestal Brasileiro. A análise das operações métricas revelou que essa bacia possui restrição para produção agropecuária, uma vez que mais de $64 \%$ da área total da bacia é ocupada por áreas de preservação permanente, se for somado ainda mais $20 \%$ de reserva legal, sobra apenas uma pequena parte para a exploração agropecuária. De acordo com os resultados, a maior parte das APPs estão ocupadas por pastagem (cerca de 68\%), não estando em conformidade com a lei. A maior parte (84\%) das estradas estão a menos de $100 \mathrm{~m}$ dos cursos d’água. Existem algumas alternativas para tornar atraente economicamente a recuperação ambiental dessa bacia, como a utilização de técnicas mais eficientes que otimizem o espaço das propriedades para a produção, possibilidade de receber pagamentos por serviços ambientais (como acontece na bacia do PCJ no município de Extrema - MG) visto que a bacia tem potencial "produtor" de água pois possui alta densidade de drenagem. Alternativa rentável e que tem sido um grande aliado na preservação dos recursos naturais é o ecoturismo. Ela tem seu exutório próximo à Rodovia Oswaldo Cruz.

\section{Referências bibliográficas:}

ASSAD, E. D.; SANO, E. E.; BEZERRA, H. S.; SILVA, S. C.; LOBATO, E. J. V. Uso de modelos numéricos de terrenos na espacialização de época de plantio. In: Eduardo Delgado Assad; Edson Eyji Sano. (Org.). Sistema de informações geográficas: aplicações na agricultura. 2 ed. Brasília: Serviço de Produção de Informações - SPI, 1993, v. , p. 311-327.

BAtistA, G. T.; TARGA, M. S.; FIDALGO, E. C. C. Banco de Dados Ambientais da Bacia do Rio Una, Bacia do Rio Paraíba do Sul. Repositório Eletrônico Ciências Ambientais, Coleção Recursos Hídricos, UNITAU. Disponível em: <http://hdl.handle.net/2315/51>. Acesso outubro de 2009. 2002. 16p.

BRASIL. Decreto-lei no 4.771, de 15 de setembro de 1965. Institui o Novo Código Florestal Brasileiro e dá outras providencias. DOU de 16 de setembro de 1965. Brasília DF. 1965.

CÂMARA G., SOUZA R. C. M., FREITAS U. M., GARRIDO J. SPRING: Integrating remote sensing and GIS by object-oriented data modeling. Computers \& Graphics, 20: (3) 395-403, May-Jun 1996.

CATElANI, C. de S.; BATISTA, G.T. Mapeamento das Áreas de Preservação Permanente do município de Santo Antonio do Pinhal, SP: um subsídio à preservação ambiental. Revista Ambi-Agua, v. 2, n. 1, p. 3043, 2007.

CHRISTOFOLETTI, A. Análise morfométrica das bacias hidrográficas. Notícias Geomorfológicas, v.9, n.18, p.19-34, 1969.

CHRISTOFOLETTI, A. Geomorfologia. Ed. Edgard Blucher Ltda., 1974 - EDUSP. 149 p.

FONTES, A. L. Caracterização geoambiental da bacia do rio Japaratuba - SE, Rio Claro. 1997. 283 p. Tese (Doutorado) - Instituto de Geociências e Ciências Exatas, Universidade Estadual Paulista. Rio claro. 1997.

LOPES, R. M.; ASSUNÇÃO, H. F.; SCOPEL, I.; CABRAL, J. B. P. Características fisiográficas e morfométrica da microbacia do córrego Jataí-GO. Geoambiente On-line, v. 1, p. 9-22, 2007.

Oliveira, I. S.; BAtista, G. T.; CATElAni, C. S. Minicurso de Área de Preservação Permanente (APP). In: Material didático utilizado no minicurso sobre APP ministrado no Encontro Água \& Floresta: O Estado da Arte em Educação Ambiental, realizado pela Secretaria Estadual do Meio Ambiente (SMA/SP) e Universidade de Taubaté, 7-9 de novembro de 2006, Taubaté, SP. Disponível em: <http://hdl.handle.net/2315/66>. Acesso em: 01 Out. 2009.

SHENG, T. C.; BARRETT, R. E.; MITCHELL, T. R. Using geographic information systems for watershed classification and rating in developing countries. Journal of Soil and Water Conservation, v.52, n.2, p.8489, 1997. 